$07 ; 08$

\title{
Роль пьезоэффекта в аномальной зависимости проводимости гетероструктуры AIGaAs/GaAs c двумерным электронным газом от расстояния между контактами
}

\author{
(C) B.E. Сизов, М.В. Степушкин \\ Фрязинский филиал Института радиотехники и электроники им. В.А. Котельникова РАН, Фрязино, Московская обл., \\ Россия \\ E-mail: vesizov@mail.ru
}

Поступило в Редакцию 2 августа 2019г.

В окончательной редакции 14 октября 2019 г.

Принято к публикации 15 октября 2019г.

\begin{abstract}
Представлены результаты экспериментальных исследований проводимости гетероструктуры $\mathrm{AlGaAs} / \mathrm{GaAs}$ с двумерным электронным газом в области температур 10-300 K. При низких температурах с уменьшением расстояния между контактами к структуре от 100 до $20 \mu \mathrm{m}$ наблюдался рост сопротивления. Для объяснения данной аномальной зависимости выполнено численное моделирование влияния пьезоэффекта в полупроводнике на проводимость канала. Показано, что необходимо учитывать кристаллографическую ориентацию канала и влияние на его потенциал удаленных пьезозарядов.
\end{abstract}

Ключевые слова: двумерный электронный газ, проводимость канала, пьезоэлектрический эффект, кристаллографическое направление, $\mathrm{AlGaAs} / \mathrm{GaAs}$.

DOI: 10.21883/PJTF.2020.02.48947.18007

При электрофизических исследованиях на гетероструктурах $\mathrm{AlGaAs} / \mathrm{GaAs}$ важно знать характеристики контактов, например контактное сопротивление к двумерному электронному газу. Одним из типичных методов измерения сопротивления контактов к тонкопленочным структурам является метод передающей линии $[1,2]$. Для него изготавливаются специальные образцы с несколькими одинаковыми контактами, расположенными на разных расстояниях друг от друга. В простой традиционной модели общее сопротивление между соседними контактами рассматривается как сумма удвоенного контактного сопротивления и сопротивления канала между ними. Если все контакты одинаковые и не влияют на соседние, а сопротивление канала прямо пропорционально величине зазора между контактами, то зависимость общего сопротивления от величины зазора будет линейной и пересекать ось ординат в точке, соответствующей удвоенному сопротивлению контакта. Однако встречаются отклонения от этой простейшей модели. Так, на структурах с GaAs иногда сопротивление между контактами растет с уменьшением расстояния между ними. Задача настоящей работы дать объяснение этой аномалии.

Из других эффектов в [3] наблюдалась зависимость сопротивления от направления протекания тока в кристалле, что объяснялось анизотропией диффузии металла контакта, анизотропией роста кристаллов металла и пьезоэлектрическим эффектом в полупроводнике, вызванным наличием на его поверхности металла или диэлектрика. А аналогичный нашему эффект описан в [4], где при протекании тока вдоль кристаллографического направления [011] гетероструктуры $\mathrm{AlGaAs} / \mathrm{GaAs}$ эксперимент описывался моделью, а при протекании тока вдоль направления $[01 \overline{1}]$ вместо снижения сопротивления с уменьшением зазора между контактами наблюдался его значительный рост. Удовлетворительного объяснения такому поведению дано не было. Ряд особенностей в структурах на основе GaAs объясняется пьезоэффектом. Моделирование пьезоэффекта описано в [5,6] для полевого транзистора на основе GaAs. Источником механического напряжения в транзисторе были слои диэлектрика, $\mathrm{SiO}_{2}$ или $\mathrm{Si}_{3} \mathrm{~N}_{4}$. Индуцированные пьезозаряды в канале транзистора приводили к сдвигу порогового напряжения. Сдвиг зависел от ориентации и длины канала. В работе [7], где источником механических напряжений служил слой фоторезиста, рассчитывался созданный пьезозарядами потенциал в канале, a в $[8,9]$ пьезоэффект влиял на дрейф характеристик вследствие химической реакции остаточного водорода с металлизацией затвора.

Для наших исследований на гетероструктурах $\mathrm{AlGaAs} / \mathrm{GaAs}$ с одномерным квантовым каналом важно было иметь хорошие омические контакты к двумерному электронному газу (2DEG) при низких температурах. Сами гетероструктуры выращивались методом молекулярно-лучевой эпитаксии на полуизолирующей подложке GaAs, на которую последовательно наносились буферный слой $\mathrm{GaAs}$ толщиной $500 \mathrm{~nm}$, слой AlGaAs $(35 \mathrm{~nm})$, содержащий два $\delta$-легированных кремнием слоя на расстояниях 20 и $25 \mathrm{~nm}$ от гетерограницы, и защитный слой GaAs $(5 \mathrm{~nm})$. Таким образом, расстояние от поверхности до двумерного электронного слоя в разрыве зон на границе $\mathrm{AlGaAs} / \mathrm{GaAs}$ было равно $40 \mathrm{~nm}$. При $4.2 \mathrm{~K}$ подвижность электронов составляла 


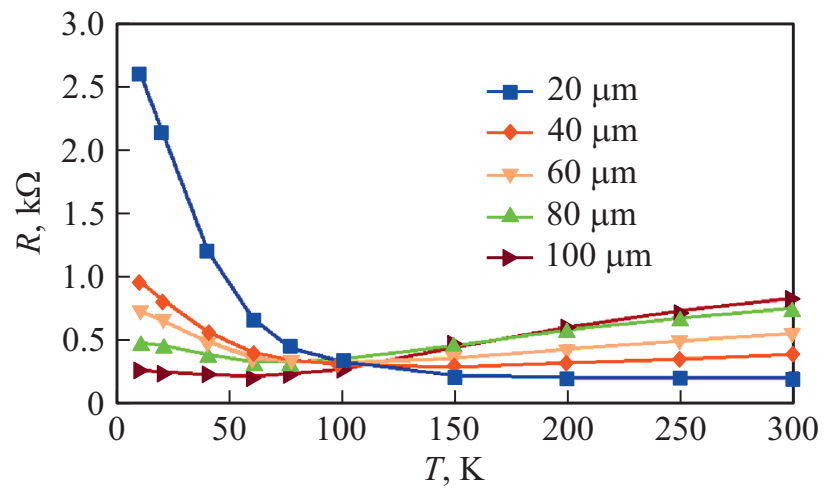

Рис. 1. Температурные зависимости сопротивления между контактами при различных расстояниях между ними для случая протекания тока вдоль направления [01ㅍ]

$3 \cdot 10^{5} \mathrm{~cm}^{2} /(\mathrm{V} \cdot \mathrm{s})$, а их концентрация $-1.2 \cdot 10^{11} \mathrm{~cm}^{-2}$. К структуре с помощью оптической литографии и вакуумно-термического испарения создавались контакты $\mathrm{Ni} / \mathrm{Ge} / \mathrm{Au}$ размером $400 \times 400 \mu \mathrm{m}$ на расстояниях 20 , $40,60,80$ и $100 \mu \mathrm{m}$. Подробнее наши исследования и технология описаны в $[10,11]$.

Измерения сопротивления между контактами с разной длиной зазора между ними проводились в температурной области $10-300 \mathrm{~K}$, при этом вольт-амперные характеристики при всех зазорах были линейными, т.е. контакты оставались все время омическими. Зависимости не имели выбросов или других косвенных свидетельств брака какого-либо контакта. На рис. 1 приведены температурные зависимости сопротивления при протекании тока вдоль направления [011] ]. При высоких температурах эти зависимости почти совпадали с аналогичными для других направлений, при этом немного отличалась величина сопротивления контакта, которое для направления [011̄] составляло $28 \Omega$ (удельное сопротивление $11.2 \Omega \cdot \mathrm{mm}$ ) при $300 \mathrm{~K}$. Но с понижением температуры для данного направления наблюдалась аномальная зависимость сопротивления от расстояния между контактами, аналогичная отмеченной в [4]. Ключевым, на наш взгляд, моментом, затрудняющим объяснение аномального низкотемпературного поведения, является несоизмеримость геометрических параметров - слишком большое расстояние между контактами по сравнению с другими характерными размерами: длиной диффузии, глубиной залегания проводящего канала, длиной свободного пробега носителей заряда и др.

Мы предположили, что за аномальную зависимость отвечает пьезоэлектрический эффект в полупроводнике, индуцируемый при охлаждении механическим напряжением на границе полупроводник-металлический контакт. Само напряжение обусловлено различием в коэффициентах теплового расширения металла и полупроводника. Особенно эффект становится заметен при уменьшении температуры ниже $120 \mathrm{~K}$.
Для численного моделирования мы использовали схему, аналогичную схеме из работ $[5,6]$ (рис. 2). Металлические контакты считаются бесконечно протяженными в стороны от контактов вдоль оси $X$. Геометрические размеры структуры вдоль оси $Y$ (перпендикулярно плоскости рисунка) также считаются бесконечно большими, что позволяет проводить расчет двумерного случая. Концентрация пьезозарядов в произвольной точке полупроводника может быть вычислена по формуле, приведенной в $[5,6]$ для ориентации [110]:

$$
N_{p z}=d_{f} \gamma_{b} \sigma\left(\frac{x_{1} z\left(x_{1}^{2}-\beta z^{2}\right)}{r_{1}^{6}}-\frac{x_{2} z\left(x_{2}^{2}-\beta z^{2}\right)}{r_{2}^{6}}\right),
$$

где $d_{f}$ - толщина нанесенного на поверхность материала, $\gamma_{b}=2 d_{14}(4-v) / \pi, d_{14}=2.69 \cdot 10^{-12} \mathrm{C} / \mathrm{N}-$ пьезокоэффициент для $\mathrm{GaAs}, \beta=(2+v) /(4-v)=0.59$ для GaAs, $v=0.23$ - коэффициент Пуассона для GaAs, $\sigma$ - величина механического напряжения, составляющая в упомянутой литературе порядка $10^{8} \mathrm{~N} / \mathrm{m}^{2}$.

Вследствие анизотропии кристалла GaAs величина $N_{p z}$ зависит от направления механического напряжения. Для направлений протекания тока [011] и [011̄] компоненты одного тензора пьезокоэффициентов равны соответствующим компонентам другого и противоположны по знаку, т.е. механическое напряжение, вызывающее при одной ориентации за счет пьезоэффекта увеличение концентрации электронов в канале, при другой ориентации будет приводить к ее уменьшению.

При моделировании было установлено, что учет влияния пьезозарядов, наведенных только в канале, недостаточен для объяснения аномалии. Необходимо учитывать заряды, индуцированные во всем объеме кристалла и сдвигающие потенциал в канале (аналогично затвору полевого транзистора). В двумерной модели вклад в потенциал точки канала от пьезозарядов с одинаковыми $x$ и $z$ вычислялся по формуле

$$
\Delta \varphi=\left(\tau / 4 \pi \varepsilon \varepsilon_{0}\right) \ln \left(l_{2} / l_{1}\right),
$$

где $\tau=N_{p z} d x d z$ - линейная плотность заряда в направлении $Y$, а $l_{1}$ и $l_{2}-$ расстояния от выбранной точки до

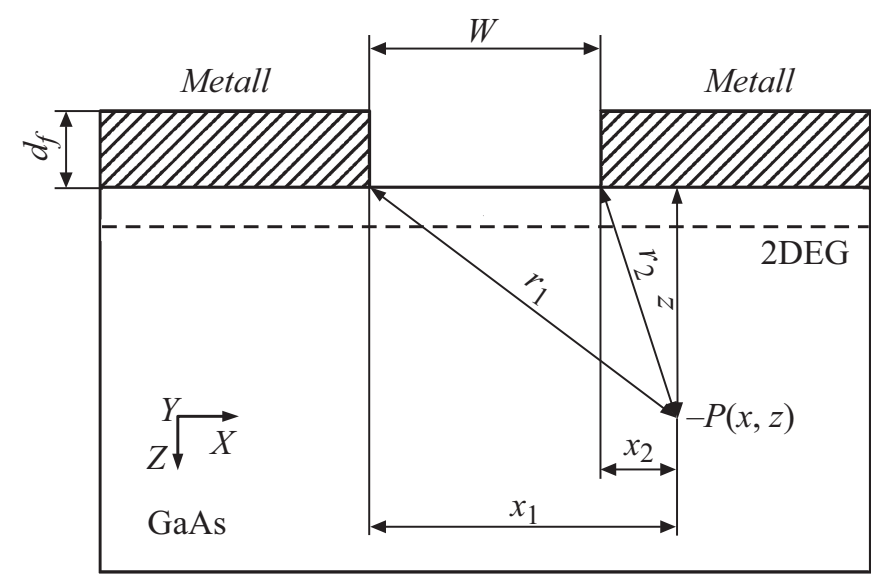

Рис. 2. Модель структуры для расчета пьезоэффекта. 


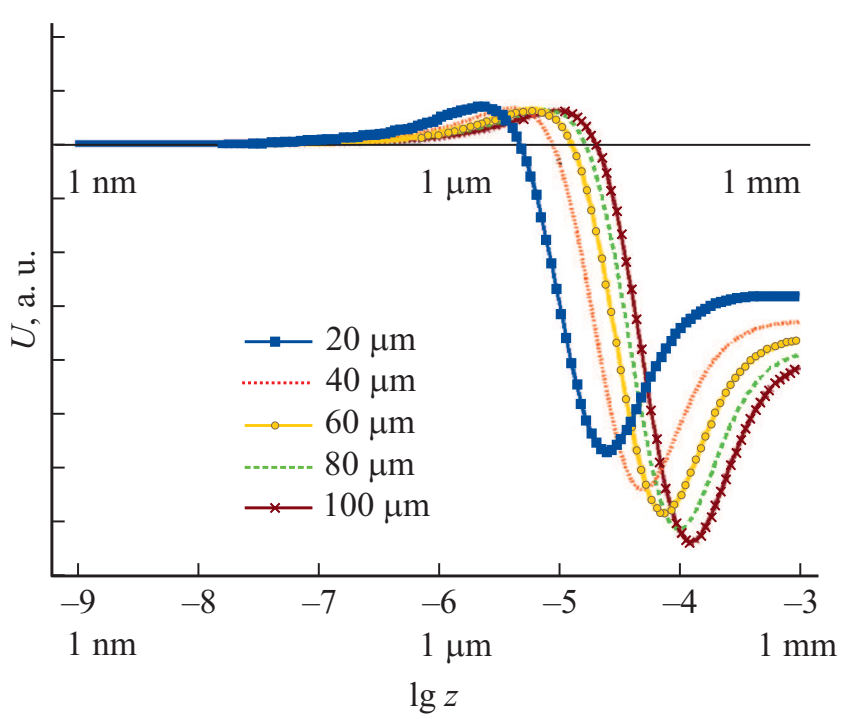

Рис. 3. Величина электростатического потенциала в центре каналов разной длины, наведенного пьезозарядами из объема полупроводника. По оси абсцисс в логарифмическом масштабе отложена глубина полупроводника, до которой учитывается вклад пьезозарядов.

контакта, принимаемого за опорный, и до рассматриваемой точки канала соответственно. На рис. 3 представлен сдвиг электростатического потенциала в центре канала при учете совокупности пьезозарядов в полупроводнике до различной глубины. Из рисунка следует, что существует область вполне реальных параметров структуры, в которой отрицательное (запирающее) напряжение в канале с малой длиной превышает напряжение в более длинном.

Проведенное нами численное моделирование подтвердило возможность объяснения с помощью пьезоэффекта аномального поведения сопротивления, а именно его увеличения при уменьшении расстояния между контактами от 100 до $20 \mu \mathrm{m}$ при глубине залегания проводящего слоя $40 \mathrm{~nm}$. В нашем случае пьезоэффект при охлаждении вызывается механическим напряжением, обусловленным различием коэффициентов теплового расширения полупроводника и металла контактов. Для двух кристаллографических ориентаций образца [011] и $[01 \overline{1}]$ полярности наведенного пьезозарядами потенциала будут противоположными. Наибольшее влияние пьезоэффект оказывает на структуры с низкой концентрацией свободных носителей заряда в канале.

\section{Благодарности}

Авторы благодарны А.И. Торопову (ИФП СО РАН) за предоставление исходных гетероструктур $\mathrm{AlGaAs} / \mathrm{GaAs}$.

\section{Финансирование работы}

Работа выполнена в рамках государственного задания.

\section{Конфликт интересов}

Авторы заявляют, что у них нет конфликта интересов.

\section{Список литературы}

[1] Reeves G.K., Harrison H.B. // IEEE Electron Dev. Lett. 1982. V. 3. N 5. P. 111-113. DOI: 10.1109/EDL.1982.25502

[2] Heiblum M., Nathan M.I., Chang C.A. // Solid-State Electron. 1982. V. 25. N 3. P. 185-195. DOI: $10.1016 / 0038-1101(82) 90106-\mathrm{X}$

[3] Kamada M., Suzuki T., Nakamura F., Mori Y., Arai M. // Appl. Phys. Lett. 1986. V. 49. N 19. P. 1263-1265. DOI: $10.1063 / 1.97381$

[4] Göktas O., Weber J., Weis J., Von Klitzing K. // Physica E. 2008. V. 40. N 5. P. $1579-1581$. DOI: $10.1016 /$ j.physe.2007.09.115

[5] Asbeck P.M., Lee C.-P., Chang M.-C.F. // IEEE Trans. Electron Dev. 1984. V. 31. N 10. P. 1377-1380. DOI: $10.1109 /$ T-ED.1984.21719

[6] Lo S.-S., Lee C.-P. // IEEE Trans. Electron Dev. 1990. V. 37. N 10. P. 2130-2140. DOI: $10.1109 / 16.59901$

[7] Larkin I.A., Davies J.H., Long A.R., Cuscó R. // Phys. Rev. B. 1997. V. 56. N 23. P. $15242-15251$. DOI: 10.1103/PhysRevB.56.15242

[8] Blanchard R.R., del Alamo J.A., Adams S.B., Chao P.C., Cornet A. // IEEE Electron Dev. Lett. 1999. V. 20. N 8. P. 393-395. DOI: $10.1109 / 55.778153$

[9] Mertens S.D., del Alamo J.A. // IEEE Trans. Electron Dev. 2002. V. 49. N 11. P. $1849-1855$. DOI: $10.1109 /$ TED.2002.804698

[10] Борисов В.И., Кувшинова Н.А., Курочка С.П., Сизов В.Е., Степушкин М.В., Темирязев А.Г. // ФТП. 2017. Т. 51. В. 11. C. 1534-1537. DOI: 10.21883/FTP.2017.11.45106.20

[11] Курочка С.П., Степушкин М.В., Борисов В.И. // Изв. вузов. Материалы электронной техники. 2016. Т. 19. № 4. C. 271-278. DOI: 10.17073/1609-3577-2016-4-271-278 